Saudi Journal of Oral and Dental Research

Abbreviated Key Title: Saudi J Oral Dent Res

ISSN 2518-1300 (Print) |ISSN 2518-1297 (Online)

Scholars Middle East Publishers, Dubai, United Arab Emirates

Journal homepage: https://saudijournals.com/sjodr

\title{
Coronavirus (COVID-19) Impact on Indian Dentists and their Practice: A Cross Sectional Study
}

\author{
Dr. Waseem Khan (M.D.S.) $)^{1}$, Dr. Suyog Shendage (M.D.S.) ${ }^{2}$, Dr. Rushda Kazi (B.D.S.) ${ }^{3 *}$ \\ ${ }^{1,2}$ Senior Lecturer, Department of Orthodontics, D. Y. Patil Dental School, Pune, India \\ ${ }^{3}$ Tutor, D.Y. Patil Dental School, Pune, India
}

DOI: $10.36348 /$ sjodr.2020.v05i08.007

| Received: 13.08.2020 | Accepted: 21.08.2020 | Published: 29.08 .2020

*Corresponding author: Dr. Rushda Kazi

\section{Abstract}

Brief Background: Dentistry is facing its darkest hour yet, with the growth and spread of the Coronavirus pandemic. Dental surgeons are at the highest risk of contracting and transmitting the Coronavirus, alongside paramedics, nurses, and other healthcare workers. Dental clinics across the country were shut for over two months. With the pandemic still on the growth curve, there is no hope of revival anytime soon, compounded by zero earnings by dental practitioners and staff at clinics. To our knowledge, no study addresses the dentist's perspective in such testing times, where they are entirely restricted to the confines of their homes. Aim: To assess the effects of COVID-19 and the lockdown on Indian Dentists and their practice. Materials and Methods: A self-designed online exploratory questionnaire of 18 questions was distributed to 400 potential responders. This cross-sectional study was conducted through an online survey questionnaire among dentists of Maharashtra in India. Dentists were enquired for demographics, experience, education and questions based on the current scenario and was used to give results among the study population. Results and Discussion: Out of the Four hundred dentists who were approached, a total of Two hundred and twenty subjects returned the questionnaire. $38.2 \%$ dentists' clinics were open but seeing lower patient volume than usual and $31.8 \%$ dentists were closed but seeing emergency patients. Also $28.2 \%$ dentists were closed and not seeing any patients. All the dentists replied in affirmative when asked if the virus and lockdown affected their practice. $69.1 \%$ dentists did attend to patients on emergency basis and the same percentage of dentists practiced teledentistry. $68.2 \%$ dentists were facing problems with their rents, wages and payments related to their practice. $80.9 \%$ of dentists were prepared to reopen their practice and $53.6 \%$ of dentists were planning to increase the treatment charges. 31.5\% of dentists had a stock of PPE which would last those 1-6 days and $25 \%$ had a stock lasting them more than a month. $47.3 \%$ were highly concerned regarding the risk of transmission of Covid-19 to themselves, their team and the patients. Summary and Conclusion: With the recent claims the Covid-19 is here to stay for a while, it is essential that dentists must be fully prepared before providing services and must attain proper awareness to limit the disease spread.

Key words: COVID-19, Coronavirus, Dentists, dental professionals.

Copyright @ 2020: This is an open-access article distributed under the terms of the Creative Commons Attribution license which permits unrestricted use, distribution, and reproduction in any medium for non-commercial use (NonCommercial, or CC-BY-NC) provided the original author and source are credited.

\section{INTRODUCTION}

More than two million Indians have now tested positive for Covid-19, according to official figures. The country confirmed the last million cases in just 20 days, faster than the US or Brazil which have higher numbers. The Chinese Centre for Disease Control and Prevention on the record pronounced novel coronavirus as the etiological agent of coronavirus disease 2019 (COVID19) on January 8, 2020. Beginning from Wuhan city, China, since last December the epidemics of COVID-19 have developed into a foremost challenging public health crisis globally $[1,2]$. The World Health Organization (WHO) affirmed COVID-19 outburst a "pandemic" on March 11, 2020 [3]. It has turned out to be a "black swan" in the language of economists, which is an infrequent and intrinsically unforeseeable incident with brutal consequences. A pandemic frequently results in worldwide recessions; moreover, the economy was already frail and in danger before the pandemic. Every facet of global trade is impacted by the virus. Nearly every sector is being affected and is bunged by this event [4]. With COVID-19 declared as a worldwide pandemic, a nationwide lockdown was implemented overnight in India on March 24, 2020. With no prior warning or anticipation, patient appointments were temporarily ceased as institutions and clinics were indefinitely closed. Dental clinics have been closed ever since lockdown processes were declared in India. Most of the dentists who comprehend the corollaries of this 
pandemic are planning to postpone reopening of their clinics for some more time period which renders into zero earnings and subsequently a very vague prospect for dentistry and the personnel at dental clinics [5]. Owing to close proximity with infected patients, the risk of getting the infection is always higher in healthcare workers [6]

Among all healthcare professionals, dental surgeons are considered at the highest risk of contracting and transmitting the corona virus [5]. Dental services due to their unique nature like generation of aerosol, sharps handling and caregiver's nearness to the oro-pharyngeal region of the patient can be attributed to these risks [1,6]. Hence, dentists have an elevated risk of taking infection from patients and probably scattering it to their near and dear ones. Furthermore, the dental clinics can most likely expose patients to cross contamination, if ample safety measures are not engaged. The reactions and action plan of dental authorities globally varied from recommending dentists to stop their practices in California, USA [7]; to declining the routine examinations in the UK [8]. The dental council of India released advisory on $16^{\text {th }}$ April 2020 stating that dentists ought to now sternly follow all modus operandi to decontaminate, disinfect and sterilize at the dental clinics as given, permitting to treat an utmost of only 3 or 4 patients in a day. The council also urges just emergency dental treatments in the near future, additionally impacting the fiscal plight of dentists [5].

COVID-19 has had a devastating impact on the dental industry, and with the pandemic still on the growth curve, and it is difficult to ascertain the extent and severity of its long-term impact at this point of time. The professional future of dental practitioners and the sustenance of their practices is a serious concern. Wages and clinic rentals have to be accounted for every month even though there have been no revenues, causing a huge socio-economic impact. Dental practitioners now face a test which they were not ready for. No management training program or dental college could have imagined this type of situation, where there is a long-standing phase of interruption [4]. With the growing knowledge of this novel disease, dental practitioners must be better primed to recognize a likely infection of COVID-19 and should also be able to refer patients having doubtful, established, or a previous infection of COVID-19 to proper treatment centers [6]. Also, healthcare facilities are essentially necessary for any society and cannot be stopped for an extended time during such pandemic conditions [9]. As soon as the lockdown measures do alleviate up finally, dentists must practice with all precautions and protocols. Therefore, the present study was carried out for evaluating the impact and effects of the virus and the lockdown on dentists and their practice in a developing country like India.

\section{MATERIALS AND METHODS}

The current cross-sectional questionnaire study was carried out among practicing dental professionals through an online survey form, in the state of Maharashtra from $15^{\text {th June }}$ to $15^{\text {th }}$ July 2020. A closeended structured questionnaire was prepared in English using 'Google docs' forms by the investigators. The dental professionals were approached with the help of social media for filling the online survey link. Exclusion criteria comprised of doctors from other medical streams, dental students and paramedical staff. The dentists were informed about the study and consent was taken. Its voluntary nature was emphasized and confidentiality was assured. This cross-sectional study utilized questions prepared pertaining to the current scenario and was framed in English.

\section{RESULTS}

Age of dentists recorded was between 23-61 years.67.3\% were females while $32.7 \%$ were males.55.5\% of respondents were M.D.S. (Masters in Dental Surgery) while $44.5 \%$ were B.D.S.(Bachelors). $79.1 \%$ of dentists had less than 5 years of experience (Fig.1).

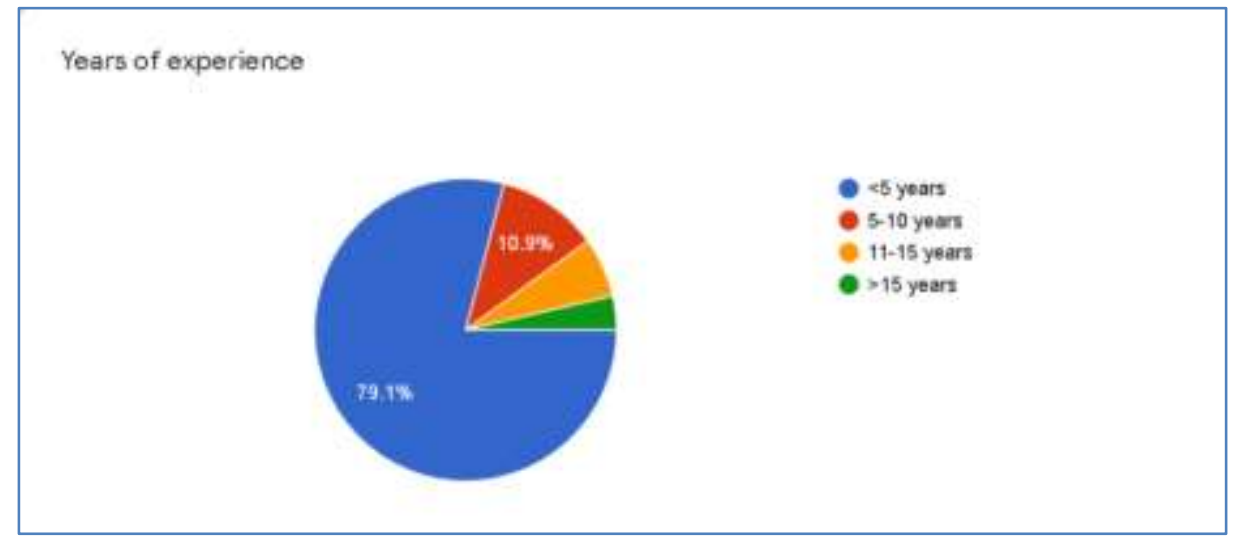

Fig-1 
$44.5 \%$ were working at a private dental clinic

(Fig.2) of which $47.6 \%$ were owners of the same.

Almost $21 \%$ were working at a private hospital/institution and $20 \%$ were working at more than 2 centers (Fig.3).

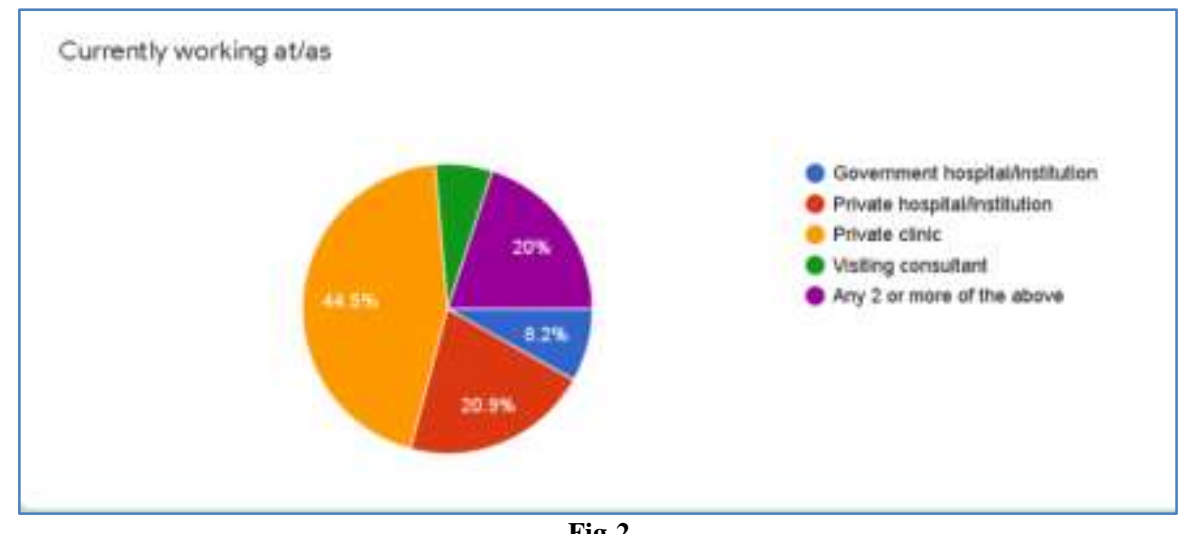

Fig-2

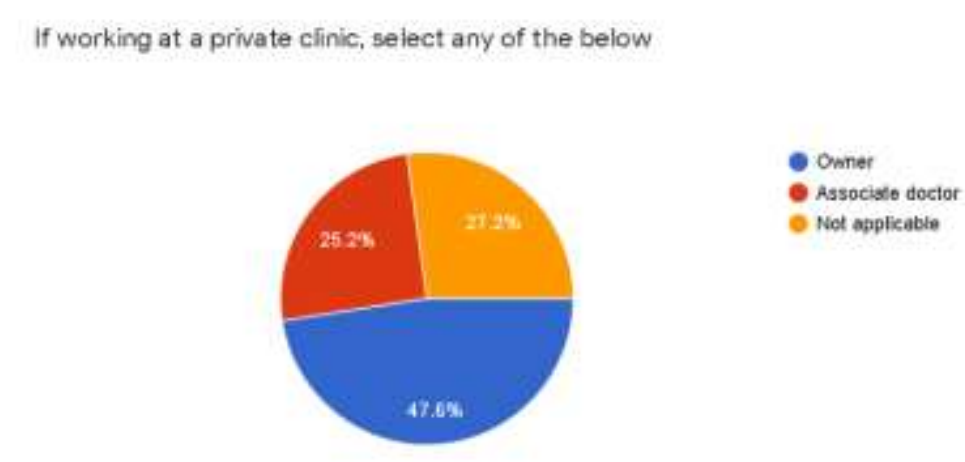

Fig-3

The current status of the respondent's dental clinic was that $38.2 \%$ dentists' clinics were open but seeing lower patient volume than usual and $31.8 \%$ dentists were closed but seeing emergency patients. Also $28.2 \%$ dentists were closed and not seeing any patients at all (Fig.4).

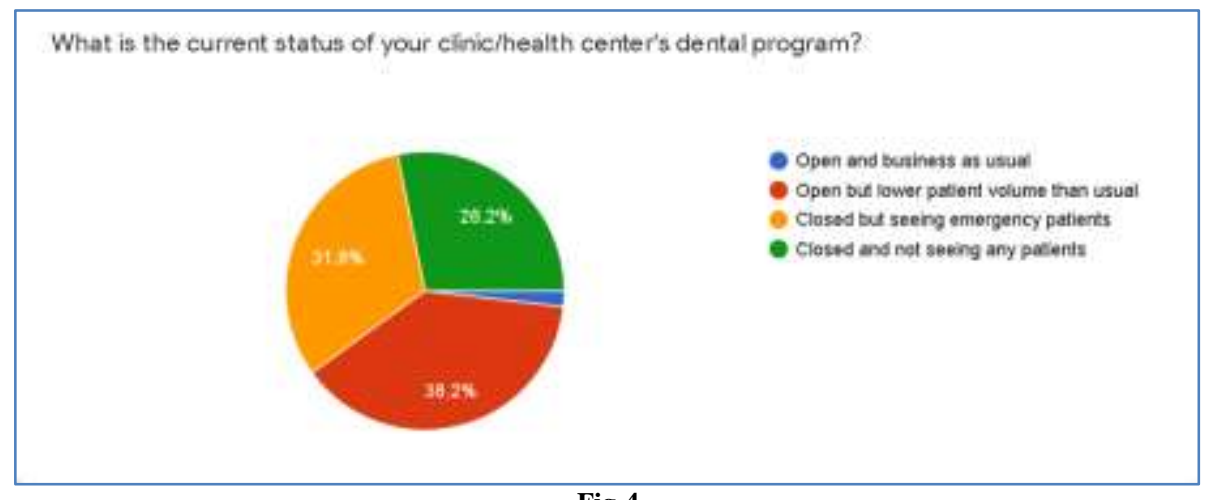

Fig-4

When asked whether the lockdown and virus affect their practice all dentists replied as Yes (Fig.5). 


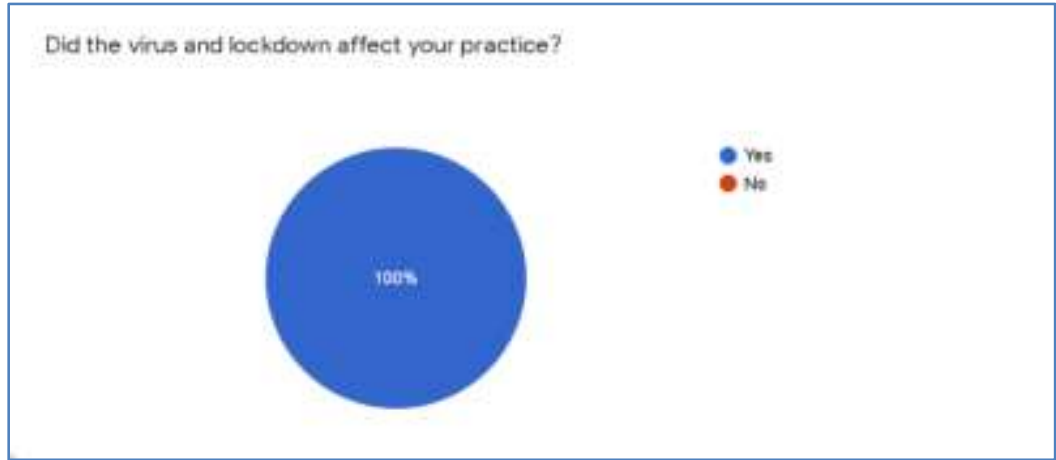

Fig-5

69.1\% dentists did attend to patients on dentists did teledentistry to address their patient's dental emergency basis (Fig.6) and the same number of concerns (Fig.7).

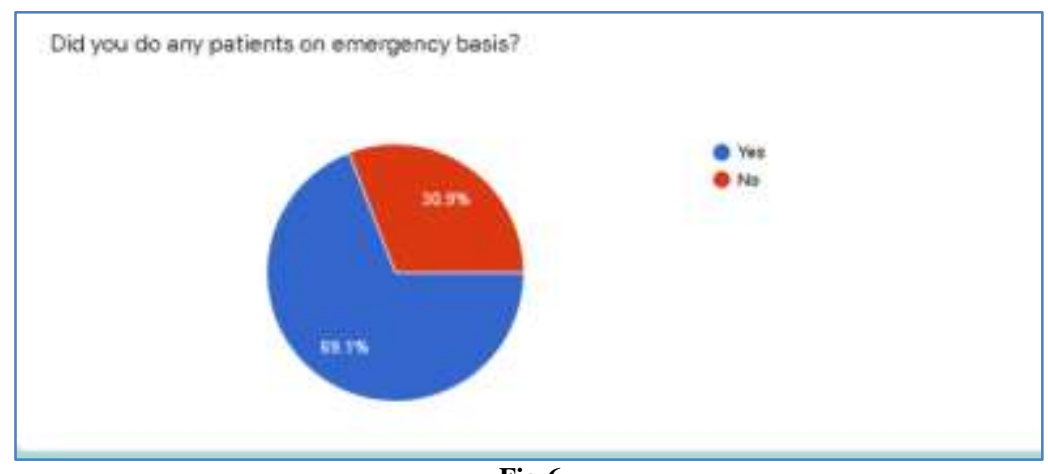

Fig-6

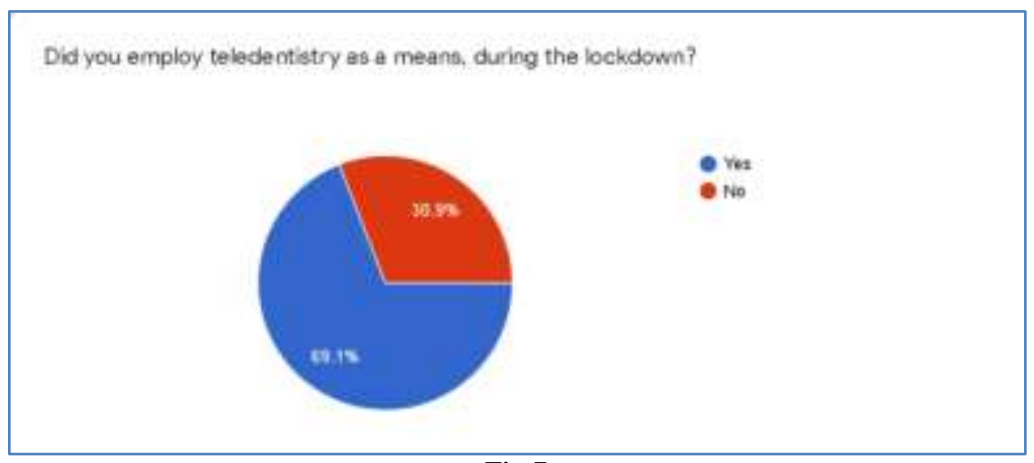

Fig-7

68.2\% dentists were facing problems with their rents, wages and payments related to their practice (Fig.8).

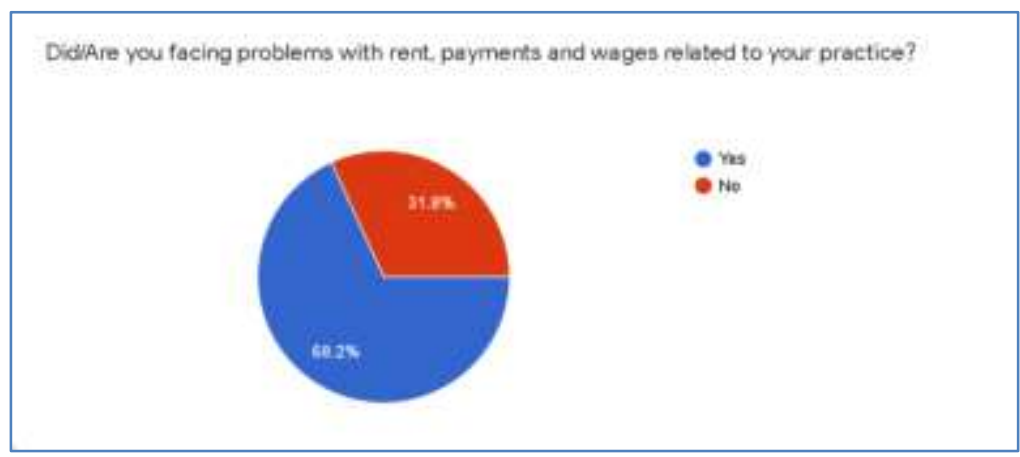

Fig-8

$80.9 \%$ dentists were prepared to reopen their clinics or practice (Fig.9) and 53.6\% were planning to increase the treatment charges on reopening their clinic (Fig.10). 


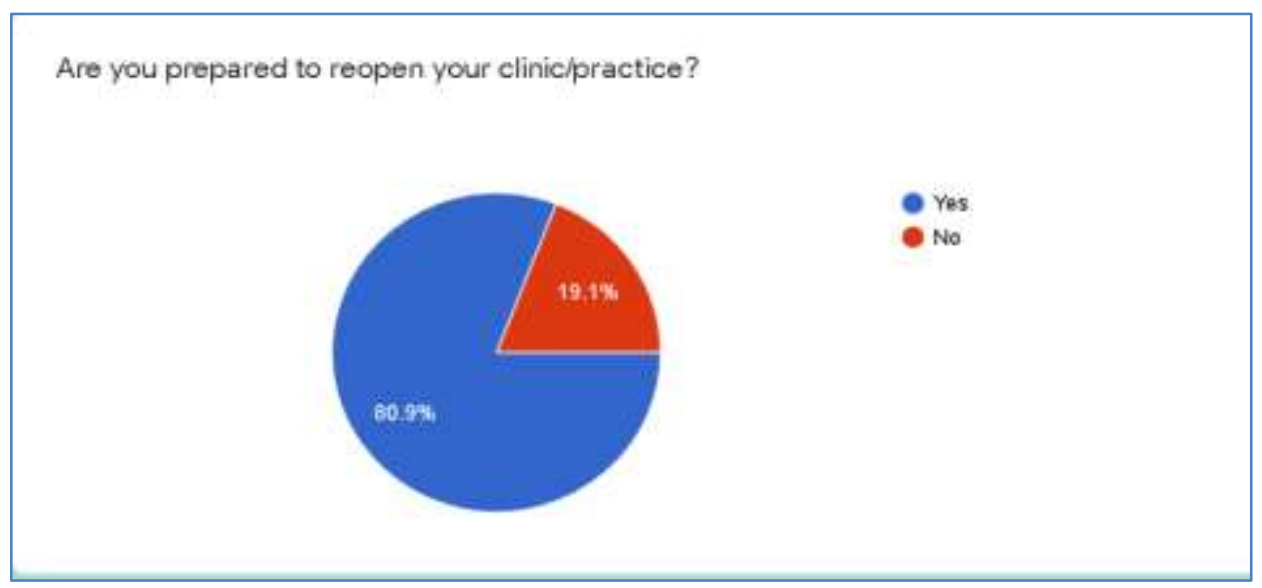

Fig-9

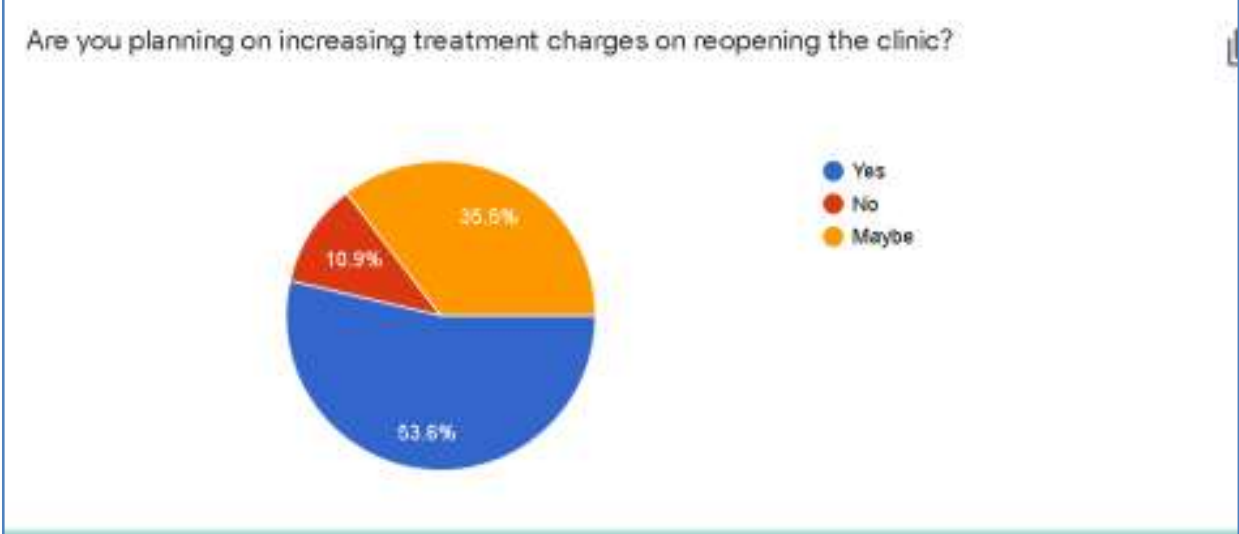

Fig-10

$31.5 \%$ respondents had PPE which would last them for around 1-6 days and 25\% had PPE which would last them for more than a month (fig.11).

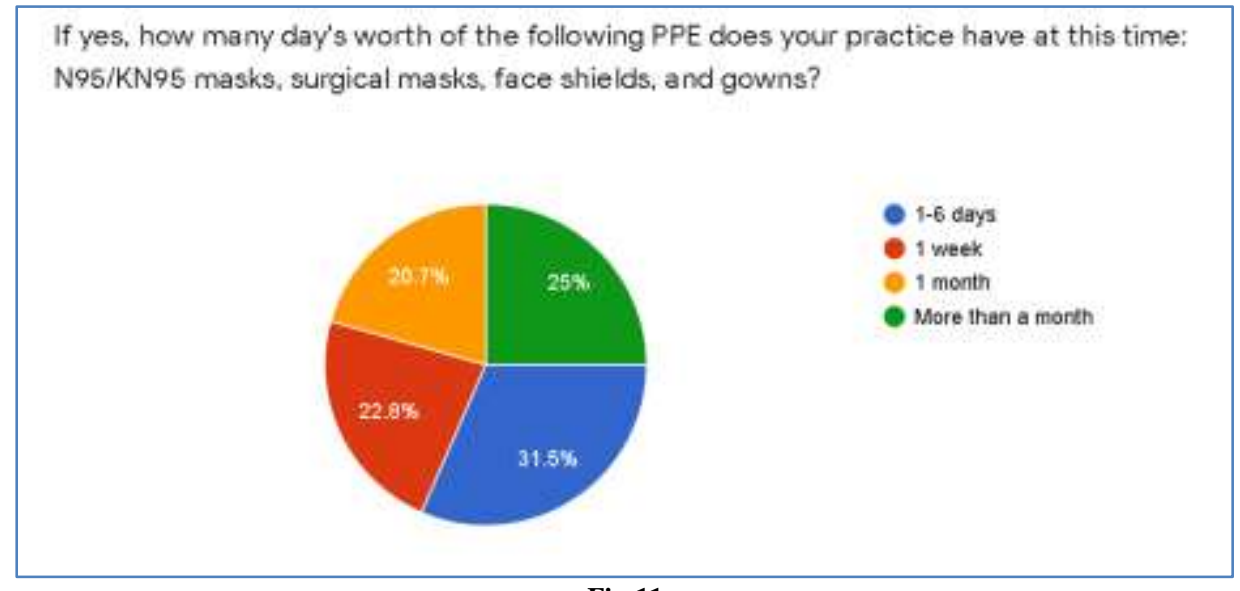

Fig-11

When asked to describe the level of concern regarding the risk of transmission of COVID-19 in their practice to patients, the dental team and themselves on a scale of $1-5$. ( 1 being least and 5 being highest) $47.3 \%$ dentists responded as highly concerned while only $4.5 \%$ were least concerned (Fig.13). 
On a scale of 1 to 5 . please describe your level of concern regarding the risk of transmission of COVID-19 in your practice to patients, the dental team and yourself. ( 1 being least and 5 being highest)

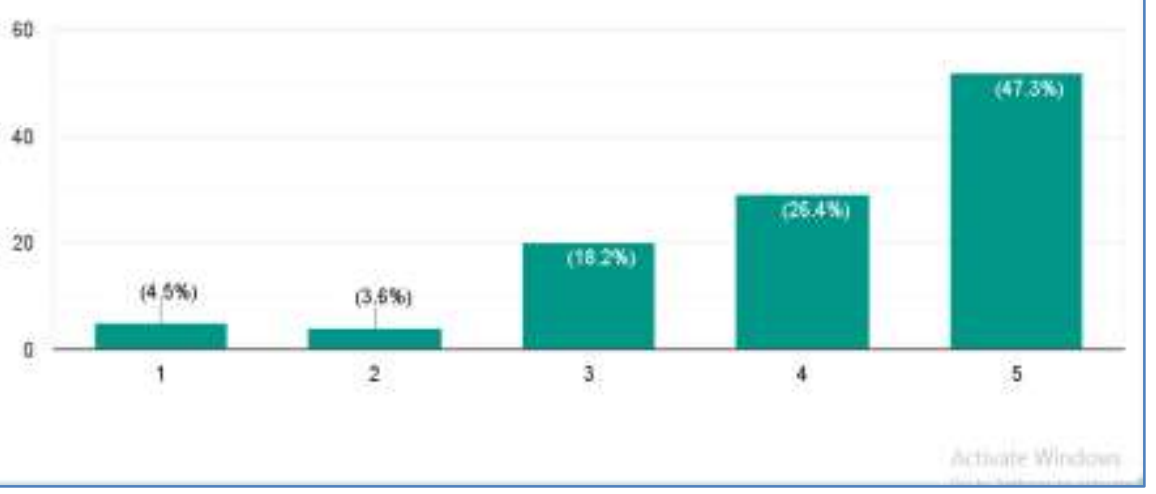

Fig-13

\section{DISCUSSION}

Intending to get an idea as to how this lockdown affected the dentists and their practice, as well as understanding the difficulties faced, the results revealed that all dentists $(100 \%)$ were in some way or the other affected by the virus and the lockdown in some or the other way but most were prepared to get back to work $(80.9 \%)$. To our knowledge, no study addresses the dentist's perspective in such testing times.

$79.1 \%$ of dentists in the study had less than 5 years of experience which meant they were new in the field and were still building their practice and settling down in dentistry. Hence many existing dental professionals have already started thinking of leaving, with yet many more to be thinking of quitting their beloved dental profession permanently and opting for alternative jobs and career fields. There have been many reports but one from UK [10], suggest this when they considered deployment of its many dental healthcare professionals including: dentists and dental nurses in hospital practice facing deployment to other new roles.

$38.2 \%$ dentists were open but seeing lower patient volume and many dentists still confused whether it was safe to practice or not, the findings, were varying. In most US states, dental practices despite having taken the precautions seriously, only as little as $1.2 \%$ did business as usual [11].

$69.1 \%$ dentists had to do emergency patients in the lockdown risking them and their families and the same number of dentists practiced teledentistry as a means to provide relief to their patients as well as for the welfare of society. Aiming to bridge the gap between healthcare services and the population, telemedicine has been recognized and regulated in Brazil as a tool to combat the pandemic of COVID-19 [12]. It favors the reduction of physical contact between professionals and patients and thus, spread of the virus. In dentistry, the following three modes of operation hold great value for oral diagnosis. Teleorientation allows professionals to perform screening, guide, and refer patients in isolation to face-to-face assistance, if needed. Telemonitoring permits professionals to visually monitor patients suspected or positive for SARS-CoV-2 who present oral lesions through photographic control. Finally, teleconsultation enables the exchange of information between professionals, assisting in the diagnosis and therapy to be instituted to the patient with greater agility and precision.

The systems available for executing telemedicine and/or teledentistry are still restricted, but represent an easy, viable, and accessible tool, useful for both health professionals and patients [13, 14]. This communication could occur through instant messaging applications (WhatsApp, Telegram, Instagram, SMS, and Messenger) and video calling applications (Google Meet, Skype, Facetime, WhatsApp). A study published by Petruzzi et al. confirmed the use of WhatsApp as a support in oral diagnosis, in which $82 \%$ of the teleconsulted cases agreed with the clinicopathological diagnosis, suggesting that it is a good option for teledentistry [14]. However, one limitation of this technology includes poor resolution of the images provided by the patient. The images must have an adequate resolution, without alterations with digital filters and must encompass the entire area of the mouth to be analyzed. These specifications will allow the correct evaluation by the oral medicine specialist. It is worth stressing that this diagnostic tool is palliative. Therefore, it is not possible to be used in all cases.

Thus, telemedicine is not a substitute for faceto-face consultation, and is mainly aimed at supporting the Public Health System (SUS) during the COVID-19 pandemic. Whenever physical consultation is required after teleorientation, the health measures of the 
regulatory agencies must be followed. In order to provide education and training to "Tomorrows' Dentists", there is an urgent need to revise dental curricula and training programs with increased emphasis on learning and practical training related to topics that could help enlarging understanding of the infectious diseases, tele-dentistry, designs of dental clinics and dental teaching hospitals that is based on evidence of relevance to safe dentistry and safe dental practice.

$68.2 \%$ dentists faced problems with payments of wages and rents related to their practice in India which showed the same trend in the US. A most recent survey involving some 20 thousand US dentists is reflected more despair and little hope. Approximately nine out of ten dental practices had less than a quarter of their typical patient volume with $82 \%$ dental practices having had less than a quarter of typical income and revenue. The decrease in earning and patients flow could certainly affect the ability of most practices to pay their employees. In fact, the inability of paying the employees over a longer time can be further sensed from the finding that $28 \%$ of dentists remained unable to pay their staff during the $3^{\text {rd }}$ week of March 2020 with another $45 \%$ who managed partial payment. Just about $27 \%$ provided full pay to their employees [11]. The US situation given here applies to everywhere in the world, where almost all dental practice have been shut either voluntarily or by governmental orders of sheltering at homes.

$31.5 \%$ of dentists had PPE which would last those 1-6 days while $25 \%$ had a stock which would last them more than a month. The Ministry of Health and Family Welfare of India has issued COVID-19 workplace recommendations. These recommendations especially focus on the need for employers to implement administrative and work practice controls, in addition to personal protective equipment (PPE) for themselves and their associates. No universal course of action is in existence for dental care prerequisite for the period of any national or global disaster, epidemic and pandemic. Due to unavailability of standard protocols, dental care has entirely stopped or drastically decreased in numerous affected countries. Furthermore, in this time of social distancing, learning the preventive measures for the COVID-19 infection is by the use of digital platform. In such scenario the burden of bearing the cost of PPE for safe practices falls on the dentists. When we talk about adapting structural changes in dentistry to meet present requirements, dentists and their assistants must mandatorily use quality and complete personal protective gear as mandated by the $\mathrm{CDC}$ at all times. However, there is a huge cost implication in procuring preventive gear including respirators etc., and the installations of HVAC A/C filters; single-use chair covers etc. Dental care clinics will require newly structured and redesigned clinics with huge investment in the right equipment to maintain strict hygiene and sterilization. If some practitioners choose to compromise on the quality of PPE used or sanitation maintained in their clinics, the resulting impact on societal health will be catastrophic. Special policies must be ensured by the government to avail these equipments for the dentist at subsidized rates.

There is apparent likelihood that dentists and other members of the dental team are having an increased risk for catching / and or transmitting this life-threatening viral infection and the other involving the respiratory system because of their involvement of seeing high volume of patients requiring close contact with them [18]. $47.3 \%$ dentists were highly concerned about the risk of transmission of COVID-19 to their patients, their dental team and themselves. At present, in the whole world, various regulatory bodies are advising the dentists to carry out merely emergency treatments. In order to stay calm and work capably, it is critical that mental coping strategies are practiced in this phase of panic and apprehension. By the meticulous following of appropriate suggestions given by the regulatory authorities this fear of dental professionals can be curtailed to a great extent.

Limitations: The study was a self-designed online questionnaire, sent to dentists through various platforms such as messages, emails, etc. However, irrespective of the non-response rate, the purpose of the study was mainly to understand the dentists and gauge their level of difficulty.

This study can thus be considered as an exploratory study to get a generalized idea on the impact of the lockdown on dentists. Data collected only from one state of the country limits the generalizability. Hence results of the current study should be inferred cautiously and not be globalized. Definite intervention planning cannot be done by merely cross-sectional studies; however a good stage for future answers is provided by such studies.

\section{CONCLUSION}

The fraternity needs to be very careful when it comes to practicing dentistry in this environment as even a small slip in following protocols and taking precautions can turn out to be very expensive. With the majority of the practices in India failing to adhere to strict hygiene protocol, sanitization and sterilization at dental practices are widely absent, further increasing the risks in performing emergency dental procedures. Dentistry today needs a complete structural change to prevent doctors as well as patients from getting infected. Apart from the significant monetary investments required to continue safe dental practice, there is also the equally important issue of proper training and process management in following these protocols to ensure minimal risk to patients and dentists alike, with no knowledge at the moment of how long COVID 19 will continue for. There is a need for 
cultural changes in the approach to dentistry, adopt tele mentoring, and shift focus to preventive dental care. Healthcare professionals can consider forming a digital hybrid learning platform to create awareness and regulate important information through social media platforms or by conducting webinars in order to influence more people positively. It is high time that we keep supporting each other in our professional family including our students, support and help patient with reduced contact, restrict the generation of aerosols and use the best personal protective equipment (PPE).We must also look out for our own mental health and wellbeing, and that of each other. We all know there should be strong belief to distance fear well away from the hope we currently have.

\section{REFERENCES}

1. Meng, L., Hua, F., Bian, Z. (2019). Coronavirus disease 2019 (COVID-19): emerging and future challenges for dental and oral medicine. J Dent Res, 99(5): 481-487.

2. Phelan, A.L., Katz, R., Gostin, L.O. (2020). The novel coronavirus originating in Wuhan, China: challenges for global health governance. JAMA.

3. Alharbi, A., Alharbi, S., Alqaidi, S. (2020). Guidelines for dental care provision during the COVID-19 pandemic. Saudi Dent J, 7;32(4):181186.

4. Bhatnagar, P. (2020). What is the 'COVID-ified' future for dentists?.

5. Bharadwaj, S. (2020). There is an urgent need to resuscitate dentistry: Dr. Srivats Bharadwaj.

6. Ather, A., Patel, B., Ruparel, N.B., Diogenes, A., Hargreaves, K.M. (2020). Coronavirus disease 19 (COVID-19): implications for clinical dental care. J Endod, 46(5):584-595.

7. CDA. (2020). Practice interruption due to COVID19 (coronavirus).

8. General Dental Council. (2020). COVID-19: latest guidance for Scotland.

9. Ahmed, M.A., Jouhar, R., Ahmed, N., Adnan, S., Aftab, M., Zafar, M.S. (2020). Fear and practice modifications among dentists to combat novel coronavirus disease (COVID-19) Outbreak. Int J Environ Res Public Health, 17(8):2821.

10. Dentistry and coronavirus (COVID-19). (2020). Moral decision-making. Coulthard $\mathrm{P} \mathrm{Br}$ Dent $\mathrm{J}$, 228(7):503-505.

11. ADA News. (2020). HPI poll examines impact of COVID-19 on dental practices. Published on 01 April 2020 . https://www.ada.org/en/publications/adanews/2020-archive/april/hpi-poll-examines-impactof-covid-19-on-dental-practices.

12. Conselho Federal de Medicina. Resolução CFM n ${ }^{\circ}$ 1.643/2002. 2020 Available from:

https://portal.cfm.org.br/index.php?option=com_co ntent $\&$ view $=$ article $\& \mathrm{id}=28636: 2020-03-19-23-35-$ $42 \&$ catid $=3$

13. Böhm da Costa, C., Peralta, F. D. S., \& Ferreira de Mello, A. L. S. (2019). How has teledentistry been applied in public dental health services? an integrative review. Telemedicine and e-Health.

14. Petruzzi, M., \& De Benedittis, M. (2016). WhatsApp: a telemedicine platform for facilitating remote oral medicine consultation and improving clinical examinations. Oral surgery, oral medicine, oral pathology and oral radiology, 121(3), 248254.

15. Meng, L., Hua, F., \& Bian, Z. (2020). Coronavirus disease 2019 (COVID-19): emerging and future challenges for dental and oral medicine. Journal of Dental Research, 99(5), 481-487.

16. The workers who face the greatest coronavirus risk. (2020). The New York Times (New York) 2020.Mar15,https://www.nytimes.com/interactive/ 2020/03/15/business/economy/coronavirus-workerrisk.html.

17. Coulthard, P. (2020). The Oral Surgery Response to Coronavirus Disease (COVID-19) Keep Calm and Carry On? Oral Surg.

18. Coulthard, P. (2020). Dentistry and coronavirus (COVID-19) - moral decision-making. Br Dent $\mathrm{J}$, 228:503-505. 